\title{
UM PRESENTE PARA O FUTURO: A DISTOPIA CONTEMPORÂNEA E SUAS INTERSEÇÕES COM A EXPERIÊNCIA PÓS-MODERNA
}

\author{
Millena Cristina Silva Portela ${ }^{1}$ \\ Maria Aracy Bonfim Serra Pinto ${ }^{2}$
}

Resumo: O advento da modernidade e o rompimento com a tradição geraram uma série de transformações, além de novas formas de concepção de mundo; a tradição saiu de cena, mas levou toda a sua solidez e as estruturas que, até então, mantinham o mundo em seu curso. Os resultados da modernidade e tudo o que vivemos hoje compõem a inusitada experiência chamada pós-modernidade. Neste percurso de descobertas, a literatura segue como um dos principais meios de exposição da expressão humana e de transformação de sua sociedade. Considerando a importância da compreensão de tais fenômenos, o presente artigo tem como objetivo o estudo da literatura distópica contemporânea como um dos gêneros que privilegiam a experiência pós-moderna através de sua crítica e reflexão das problemáticas deste conturbado tempo, assim buscamos aporte teórico nas obras de Bauman (2001) e Harvey (2008), Gregory Claeys (2013) (2017), Baccolini e Moylan (2003), Santos (2004) e Debord (2005).

Palavra-chave: Distopia; Pós-modernidade; Literatura.

Abstract: The advent of modernity and the break with the tradition led to a series of transformations, as well as new ways of conceiving the world. The tradition left the scene, but it took all its solidity and the structures that, until then, had kept the world in its course. The results of modernity and everything that we live today integrate this unusual experience which we call postmodernity. In this path of discovery, the literature persists as one of the main means to expose human's expression and to promote society transformation. Considering the importance of understanding these phenomena, the present article aims to study contemporary dystopian literature as one of the genres that privileges the postmodern experience through its critique and the reflection of the problems of this troubled time, thus we sought theoretical contribution in the works of Bauman (2001), Harvey (2008), Gregory Claeys (2013) (2017), Baccolini e Moylan (2003), Santos (2004) and Debord (2005).

Keywords: Dystopia; Postmodernity; Literature.

1 Graduada em Letras, com habilitação em língua inglesa e suas respectivas literaturas, pela Universidade Federal do Maranhão. E-mail: lennieportela@gmail.com

2 Professora Adjunta no Departamento de Letras da Universidade Federal do Maranhão onde ministra disciplinas de literaturas de língua inglesa. E-mail: aracybonfim@gmail.com 


\section{CONSIDERAÇÕES INICIAIS}

Por mais estranha que a ideia da modernidade como um projeto sólido possa parecer comparado às experiências das últimas décadas, ela não tinha como intuito a fragmentação e diluição definitiva de todas as concretudes que sustentavam o antigo mundo. No entanto, era preciso um rompimento com o passado e com qualquer tipo de ordem precedente, e a modernidade tem seu ponto de partida quando "o espaço e tempo são separados da prática da vida e entre si" (BAUMAN, 2001, p.15). Segundo Harvey (2008), a modernidade era um projeto que visava, através do esforço livre e criativo, a emancipação humana e o enriquecimento da vida diária. A concepção era que, através do domínio científico da natureza e da organização do mundo a partir da razão (e aqui excluem-se definitivamente os mitos e a religião), o ser humano estaria finalmente liberto do elo de necessidade e medo inspirados pela natureza e do seu próprio lado sombrio (HARVEY, 2008, p.19). Assim seria construída a nova e melhorada ordem mundial, onde finalmente conseguiríamos viver o nosso pleno potencial e construir um novo mundo. Os iluministas foram alguns dos praticantes do projeto da modernidade e alguns dos maiores responsáveis pelo caráter otimista atribuído ao modernismo em seus séculos iniciais. Obviamente, com o passar do tempo e com os acontecimentos devastadores do século XX, o otimismo anterior caiu por terra e a agenda de destruição (criativa) começou a ser seriamente aplicada: o rompimento com a tradição é mais que definitivo, ele é gerador da fragmentação e do desespero pela criação (ou redefinição) de qualquer que seja este novo humano, este novo momento. Este trajeto e sua influência direta nos produtores de arte (de cultura) inspira a responsabilidade urgente por instaurar a mudança, essa é inclusive uma de suas ambíguas ideias: a necessidade de ser o fixo (o eterno) e a metamorfose. O que se sucede após tais rompimentos e fragmentações é uma série de movimentos e substituições propícios para a liquefação que gerarão a ascendência da ordem (do capital) como hoje a conhecemos, a revolução tecnológica, o fenômeno das massas e tudo o que diz respeito à esfera líquida. O pós da modernidade é que se sucedeu e o que ainda estamos vivendo.

A conjuntura caótica que reina nos últimos séculos produziu uma diversidade de novos gêneros e subgêneros literários, mas talvez nenhum deles se relaciona tão harmonicamente com a pós-modernidade quanto a distopia: quando se trata da exploração das condições pós-modernas e os vetores que a mantêm em movimento, o gênero distópico é profundamente contemplativo. Ainda que essencialmente pós-moderno, o lado sombrio da utopia tem história; Raffaella Baccolini e Tom Moylan (2003) definem quatro variações do gênero: a primeira delas surge no século XX, com o lançamento de algumas das obras que conhecemos hoje como clássicos da distopia, entre elas Admirável Mundo Novo (1931), de Huxley e 1984, de Orwell (1949). A segunda variação surge entre os anos 60 e 70, em meio ao pensamento ecológico e feminista, depois de um retorno das narrativas utópicas: cientes do histórico caráter limitador e idealista que a utopia tinha até o momento, autores do gênero procuraram promover uma transformação em suas formas tradicionais: enquanto mantinham as visões de futuros melhores (sonho utópico), criaram fins mais alternativos e inclusivos, dando vida às chamadas "utopias críticas", que foram representadas por autores como Ursula K. Le Guin, Joanna Russ, Marge Piercy, Samuel R. Delany, Ernst Callenbach, 
entre outros. A terceira variação, já na década de 80 (sob o impacto da virada do conservadorismo e implantação de suas políticas na esfera popular), configura-se pelo fim abrupto das "utopias críticas" e um ressurgimento significante das narrativas distópicas. O "aniversário” de 1984 ajudou a reacender o interesse geral pelas possibilidades da distopia (pois as "profecias" pareciam estar se tornando reais), bem como o lançamento de O Conto de Aia (1985), de Margaret Atwood que relembra os clássicos do gênero, ao mesmo tempo em que os questiona e abre espaço para novas direções. Baccolini e Moylan atribuem a nova onda do gênero cyberpunk, escrita majoritariamente por mulheres e que toma um rumo diferente do seguindo pelo gênero até então, por abrir as portas para uma narrativa distópica substancialmente crítica e política. A última variação diz respeito às "distopias críticas", as distopias contemporâneas, cuja maior particularidade está na superação da limitação do modelo clássico - que buscava fundamentalmente a crítica do presente a partir de um futuro pessimista - através da reflexão de novas formas para a transformação da realidade.

Nesse percurso, as distopias ascenderam de uma tímida produção até que se tornasse um dos gêneros mais populares da atualidade. Na contemporaneidade, as narrativas pós-apocalípticas conquistaram espaço nas artes e, em suas versões críticas, acabam por contemplar também a literatura distópica. A preferência popular por esse tipo de narrativa é reafirmada todos os dias através de plataformas online de literatura, vídeos, resenhas em blogs e até mesmo como simbologia para manifestações públicas, como aconteceu em 2014, na Tailândia ${ }^{3}$. Os clipes musicais This is America, de Childish Gambino e Boca de Lobo, do brasileiro Criolo, lançados em 2018, fortificam a era dourada das distopias ao utilizarem de seus moldes para a crítica política e social dos últimos eventos do ano. Considerando a valorização à experiência pós-moderna e as possibilidades e revelações sobre a conjuntura que estas narrativas possam apresentar, o presente trabalho tem como objetivo a análise do gênero distópico na contemporaneidade, principalmente no que diz respeito à sua relação de crítica e à tradução da experiência do sujeito pós-moderno. Para isso, recorreremos a breves análises de obras como Jogos Vorazes (2010), de Suzanne Collins; Fahrenheit 451 (2012), de Ray Bradbury; Feios (2015), de Scott Westerfeld, e da série da plataforma Netflix: Black Mirror (2011).

\section{PÓS-MODERNIDADE EM SELFIE}

Antes da "era dourada" da distopia ter início, eram as narrativas de lugares e sociedades ideais, as famosas utopias, que ocupavam um espaço de privilégio na literatura. Apesar de sua pré-história, e aqui podemos apontar a República, de Platão como parte dela, é apenas com Thomas More e seu livro Utopia que o termo homônimo começa a ser utilizado. O termo criado por More para nomear a famosa ilha presente em sua obra se origina de dois termos gregos, "ou" e "topos", que juntos se tornam "não-lugar" ou "lugar que não existe”. Utopia dá início à tradição de narrativas literárias abordando sociedades ideais, ou "radicalmente melhoradas", usualmente contendo alguma espécie de contemplação crítica

3 Manifestantes utilizaram uma saudação de "três dedos", um sinal de luto, resistência e protesto dos livros Jogos Vorazes, como forma de protesto pacifico contra o golpe de estado de 2014. Fonte: <<https://www.bbc.com/news/av/world-asia-27691750/thai-demonstrators-using-hunger-games-protest-sign >> Acesso em 24 de nov. 2018. 
da sociedade vigente, colocando em perspectiva como tal sociedade seria segundo os ideais (do autor e da época) do que é melhor.

Embora por vezes possa servir como sinônimo para irreal e inatingível, a Utopia de More não era uma narrativa, muito menos a descrição, do Paraíso já que se trata de uma proposta de redenção do homem por si mesmo, na medida de que é este o responsável pela transformação no mundo imaginário apresentado pelo autor. $\mathrm{O}$ fato de as utopias literárias retratarem uma idealização não significa que tal exercício represente o melhor para todos; a percepção de problemáticas depende, fundamentalmente, do lugar que se ocupa na ordem das coisas. A exemplo temos a presença da escravidão e da prática da colonização na ilha idealizada por More. Certamente para o autor (e para a época) tais práticas eram, no mínimo, naturais, ou um sacrifício para um fim exemplar (por isso a transposição para a obra), embora para os sacrificados a percepção possa (deva) ser completamente diferente.

Em alguns casos, o ideal utópico já deixa de representar uma aspiração, para ser refletido como projeto, um modelo. Assim, alimentadas por tal fenômeno, narrativas como a de More se tornam cada vez mais populares, afinal a busca pelo ideal impulsiona os homens desde o início dos tempos. Dessa forma não é uma surpresa que utopias sociais, como o nazismo, o comunismo e o fascismo, tenham sido, de fato, aplicadas.

É com o objetivo de ser basicamente o lado sombrio da utopia que a distopia ascende. Segundo Clayes (2017, p. 4), grande parte do que associamos à "distopia" é um fenômeno moderno unido ao pessimismo secular. Para o autor, tais visões apocalípticas existem pelo menos desde 1000 a.C. O próprio termo grego apokalypsis indica a revelação do destino da humanidade.

A palavra distopia deriva de dois termos gregos, "dis" e "topos", que podem ser traduzidos por "lugar ruim", "lugar desprezível" ou "lugar não-favorável". Foi cunhado em 1747, quando ainda era soletrado "dustopia" e definido em 1748 como "um país infeliz", entretanto só foi utilizada pela primeira vez (segundo registros) por John Stuart Mill, em 1868, quando discursou ao parlamento britânico e a usou para se referir à oposição de algo ideal, utópico. A distopia pode servir para referenciar a realidade, assim como um modelo literário (sua forma mais popular), embora, diferente da utopia, não seja comum encontrá-la como uma ideologia (ao menos não nos mesmos moldes da ideologia utópica). Essencialmente, a distopia pode ser identificada como uma "utopia fracassada" (CLAEYS, 2017, p.5), um resultado direto dos regimes autoritários e totalitários do fim do século XX, famosos pela repressão, a centralização do poder e a violência:

Here it (dystopia) typically means a regime defined by extreme coercion, inequality, imprisonment, and slavery. Often this is described as some concept of collectivism run wild, though some include conformist tendencies in liberal societies which encourage egalitarian repression and intolerance. Many authors, however, simply equate 'totalitarianism' with 'dystopia'. Thus, to Steven Rosefielde, Stalinism was simply an 'infernal dystopia', and dystopia itself, particularly 'the communist 
dystopia', is defined as: 'The antithesis of Utopia. A hellish state brought about by attempts to construct unrealizable ideal systems (CLAEYS, 2017, p. 5) ${ }^{4}$.

Distopia e utopia não só compartilham uma semelhança etimológica, mas se relacionam diretamente no que diz respeito à composição. Diversas vezes, é no ideal utópico que as primeiras sementes da distopia são plantadas; o cenário utópico requer domínio e controle para que chegue ao seu fim harmônico, assim ilhas paradisíacas são "civilizadas”, povos "bárbaros" são colonizados, um sistema governamental é implementado, limites espaciais são impostos. A utopia de alguns normalmente será a distopia de outrem.

Embora a utopia seja aquela que nos acompanha desde o início dos tempos, é a distopia que tematiza a contemporaneidade. Desde a popularização do gênero com as distopias clássicas e as distopias políticas do século XX, a produção artística em torno dele (do gênero) tem se tornado massificada, diversificada e, sobretudo, global; já é possível encontrar pelo menos uma produção distópica proveniente de um continente do mundo, assim não é de forma leviana que a distopia seja denominada como um fenômeno contemporâneo da literatura. Os jornais The New Yorker ${ }^{5}$ e El País ${ }^{6}$ nomeiam tal fenômeno como a "era dourada" das distopias e talvez esse seja um título adequado para a situação, apesar de que, no caso das matérias, pelo menos uma das autoras utilize o título para atestar certo "fracasso" do gênero.

A distopia não é um gênero ideal, por mais que seu conteúdo seja uma espécie de ideal deturpado, essa é uma característica óbvia quando se leva em consideração as suas origens, e ela se torna mais problemática por se tratar da imaginação de um futuro perdido, um relato altamente pessimista do presente ou a combinação de ambos. Aliada à tendência que domina a literatura contemporânea, temos uma união esmagadora: é difícil encontrar uma possibilidade e/ou temática pessimista que a distopia não tenha explorado. Analisando-a na contemporaneidade, é notável que o gênero extrapolou as configurações concedidas a ele no século passado, bastante perceptíveis nas obras distópicas clássicas, que se concentravam em retratar o presente em um futuro pessimista. As distopias contemporâneas, por sua vez, são, sobretudo, críticas:

By self-reflexively borrowing specific conventions from other genres, critical dystopias more often blur the received boundaries of the dystopian form and thereby expand its creative potential for critical expression. Drawing on the feminist criti-

\footnotetext{
4 Aqui (distopia) normalmente significa um regime definido por extrema coerção, desigualdade, aprisionamento e escravidão. Frequentemente isso é descrito como algum conceito de coletivismo, mas alguns incluem tendências conformistas nas sociedades liberais que encorajam a repressão igualitária e a intolerância. Muitos autores, no entanto, simplesmente igualam o "totalitarismo" à "distopia”. Assim, para Steven Rosefield, o stalinismo era simplesmente uma "distopia infernal", e a própria distopia, particularmente "a distopia comunista", é definida como "A antítese da utopia". Um estado infernal causado por tentativas de construir sistemas ideais irrealizáveis (tradução nossa).
}

5 LEPORE, Jill. A Golden Age for Dystopian Fiction. Disponível em <https://www.newyorker.com/magazine/2017/06/05/a-golden-age-for-dystopian-fiction>> Acesso em 01 de Set. 2018.

6 RODRIGUEZ, Aloma. A nova era dourada das distopias. Disponível em: <https://brasil.elpais.com/brasil/2017/10/06/ cultura/1507305334_572081.html >> Acesso em 01 de Set. 2018. 
cism of universalist assumptions - fixity and singularity, and neutral and objective knowledge - and recognizing the importance of difference, multiplicity, and complexity, of partial and situated knowledges, as well as of hybridity and fluidity, the critical dystopias resist genre purity in favor of an impure or hybrid text that renovates dystopian sf by making it formally and politically oppositional ${ }^{7}$ (BACCOLINI and MOYLAN, 2003, p. 8).

As distopias contemporâneas costumam envolver tanto aspectos políticos quando ambientais e tecnológicos, uma mistura de três tipos de narrativas distópicas identificadas por Claeys (2017) em uma de suas obras dedicadas ao gênero. O propósito central dessas narrativas é a crítica, majoritariamente, às atitudes (falhas) humanas, abarcando, dessa forma, um grande número de possibilidades. A qualidade mais interessante em relação ao gênero, no entanto, é a sua capacidade de exploração de problemáticas vigentes. Por já ter sido caracterizado como um gênero do futuro, diversas vezes, a distopia é considerada apenas por este aspecto, quando o grande peso da sua crítica se encontra na reflexão do presente, transportada para um lugar-nenhum, em um tempo ainda inexistente. Excluindo as possibilidades, o que resta é a porção ameaçadora do hoje. Curiosamente a distopia parece fazer uma espécie de exercício de metamodernismo onde a contemporaneidade, e por ela podemos também entender pós-modernidade, narra e critica a si mesma.

Em seu livro Tudo que é sólido se desmancha no ar: a aventura da modernidade (1982), Marshall Berman descreve a experiência moderna como "encontrar-se em um ambiente que promete aventura, poder, alegria, conhecimento e autotransformação (...), mas ao mesmo tempo ameaça destruir tudo o que temos, tudo o que sabemos, tudo o que somos" (1982, p. 9). Apesar de estar se referindo ao um tempo (passado) e não a um gênero, Berman conseguiu descrever de forma precisa um dos caminhos de intersecção entre a pós-modernidade e o gênero distópico. Nenhuma distopia se origina totalmente do desastre, mas de ideais ordenadores e utópicos que, por algum motivo, falham no acontecimento de sua concretização. E, novamente, deve-se lembrar: a ordem moderna surge como um projeto de ser uma versão melhorada, "verdadeiramente sólida" (BAUMAN, 2000, p. 10), da tradição, todavia seu resultado, como se pode comprovar, é líquido.

É a partir dessa série de fracassos, talvez, que o temido e criticado pessimismo da distopia se origina, anunciando-nos também um segundo ponto de intersecção entre a pósmodernidade e o gênero distópico: a literatura sobre a pós-modernidade e a experiência pós-moderna é, quase que em unanimidade, pessimista, como é possível notar nas palavras de Jair Ferreira dos Santos:

\footnotetext{
7 Pelo empréstimo auto-reflexivo de convenções específicas de outros gêneros, as distopias críticas mais frequentemente desfocam os limites herdados da forma distópica e, assim, expandem seu potencial criativo para expressão crítica. Baseando-se na crítica feminista de pressupostos universalistas - fixidez e singularidade, e conhecimento neutro e objetivo e reconhecendo a importância da diferença, multiplicidade e complexidade, dos conhecimentos parciais e situados, bem como do hibridismo e fluidez, as distopias críticas resistem a pureza do gênero em favor de um texto impuro ou híbrido que renove o distópico sf tornando-o formal e politicamente opositivo (tradução nossa).
} 
Enfim, o pós-modernismo ameaça encarnar hoje estilos de vida e de filosofia nos quais viceja uma idéia, tida como arqui-sinistra: o niilismo, o nada, o vazio, a ausência de valores e de sentido para a vida. Mortos Deus e os grandes ideais do passado, o homem moderno valorizou a Arte, a História, o Desenvolvimento, a Consciência Social para se salvar. Dando adeus a essas ilusões, o homem pós-moderno já sabe que não existe Céu nem sentido para a História, e assim se entrega ao presente e ao prazer, ao consumo e ao individualismo (SANTOS, 2004, p.10).

Tais caminhos de intersecção entre gênero e tempo nos levam a levantar a hipótese de que, quando se trata da pós-modernidade, estamos muito mais para a distopia que para a utopia, como era o caso dos nossos predecessores modernos. Assim a identificação e o fascínio pelos cenários devastadores das narrativas distópicas não surgem aleatoriamente ou são (apenas) frutos da tendência: parece ser mais uma disposição orgânica, afinal, a única certeza humana é que existe um fim.

Uma das obras primordiais da ficção distópica contemporânea não pertence propriamente à Literatura, trata-se de uma série da plataforma de streaming Netflix escrita por Charlie Brooker e lançada em meados de 2011: Black Mirror. A referência à importância de Black Mirror na configuração das narrativas distópicas contemporâneas pode ser resumida em um aspecto que parece ser compartilhado por todas do gênero: verossimilhança. Evidentemente o gênero distópico se fundamenta na possibilidade, mas enquanto nas narrativas clássicas o leitor ainda podia manter certo distanciamento, alicerçado pela grande diferença temporal e pelo avanço tecnológico ainda em desenvolvimento, na contemporaneidade, isso dificilmente é possível.

As temáticas tratadas na série de Brooker focam (mas não se restringem) (a)os efeitos da tecnologia e suas vertentes nas vidas dos indivíduos, como eles a concebem e como a utilizam. No primeiro episódio da terceira temporada, "Nosedive", somos apresentados a um futuro onde a existência social das pessoas no mundo é legitimada por uma espécie de rede social regida por imagens e, o mais importante, pela classificação que os usuários concedem uns aos outros. Além da óbvia reputação entre os outros habitantes da distopia de Black Mirror, essa espécie de classificação social vai influenciar nos empregos que as pessoas conseguem (ou não) na sua manutenção, no círculo social dessa pessoa, na compra e venda de imóveis, nos relacionamentos, na vida.

Certamente "Nosedive" soa um sino de reconhecimento, uma pista de identificação e então um golpe certeiro: a rede social Instagram é a que mais próxima se encontra do protótipo apresentado por Brooker, mas o funcionamento de qualquer rede social contemporânea pode preencher as categorias de semelhança entre a rede social perturbadora de Black Mirror e as que usufruímos na atualidade. A questão que remanesce, entretanto, é a seguinte: o que nos diferencia dos sujeitos da distopia de Black Mirror?

Entre Bauman com a teoria da liquidez e Guy Debord com sua Sociedade do Espetáculo, relações frágeis e regidas por imagens, a coisificação do homem e a absoluta monomania do consumo já foram caracterizadas como atributos pós-modernos. A literatura distópica da contemporaneidade (assim como alguns clássicos do gênero) contempla, das mais diversas formas, estes aspectos de nosso tempo. Em Admirável Mundo Novo, de Aldous Huxley, 
temos a famosa máxima: "Mais vale acabar que consertar" (2014, p. 75) que faz alusão ao movimento da ordem do capital e do consumo na vida dos sujeitos, pelo menos desde a invenção do capitalismo, que, aliado ao poder da mídia e da imagem na pós-modernidade, é devastador, espetacular.

O jogo de imagens, para o consumismo, funciona de forma bastante eficaz, pois o sujeito não precisa só obter; ele precisa obter aquele produto, ele precisa ter aquele rosto, ele precisa comprar aquele sonho. Esse processo funciona, sumariamente, em conjunto, já que o pertencimento que determinado sujeito procura parte de um grupo ou de uma sociedade. O consumo passa a ser a chave para a obtenção dos componentes daquela identidade e então, daquele status e, por fim, daquele mundo: o do espetáculo. "Consumo, logo sou" e só assim se é feliz:

[...] ter e apresentar em público coisas que portam a marca e/ou o logo certos e que foram obtidas nas lojas certas é basicamente uma questão de adquirir e manter a posição social que eles detêm ou a que aspiram. A posição social nada significa a menos que tenha sido socialmente reconhecida - ou seja, a menos que a pessoa em questão seja aprovada pelo tipo certo de "sociedade" (cada categoria de posição social tem seus próprios códigos jurídicos e seus próprios juízes) como um membro digno e legítimo - como "um de nós" (BAUMAN, 2009, p. 21)

O Espetáculo teorizado por Guy Debord em 1967, pessimista e duramente sincero para a época, não parece de forma alguma uma teoria para a contemporaneidade: ele é uma tradução direta dos efeitos que o capitalismo trouxe para o mundo, da supervalorização da representação e da alienação causada pela mídia. Por isso ele ganha a relevância que, nas sociedades tradicionais, os mitos e a religião ganharam, principalmente no sentido de que o "espetáculo é a reconstrução material da ilusão religiosa" (DEBORD, 2003, p. 20). Nas narrativas distópicas Jogos Vorazes (2008), de Suzanne Collins e Feios (2005), de Scott Westerfeld, a condição absoluta que a mídia e a imagem possuem no mundo pós-moderno é explorada através da criação de um futuro onde crianças lutam até a morte pelo bem do entretenimento em um extremamente popular reality show, - chamado Jogos Vorazes - e uma cidade futurística onde todas as pessoas precisam passar por uma série de mudanças (plásticas) cirúrgicas, assim que completam a idade de dezesseis anos, com o intuito de manter o padrão, reduzir conflitos e garantir a harmonia em sociedade:

Lá onde o mundo real se converte em simples imagens, as simples imagens tornam-se seres reais e motivações eficientes de um comportamento hipnótico. $\mathrm{O}$ espetáculo, como tendência para fazer ver por diferentes mediações especializadas o mundo que já não é diretamente apreensível, encontra normalmente na visão o sentido humano privilegiado que em outras épocas foi o tato; o sentido mais abstrato, e o mais mistificável, corresponde a abstração generalizada da sociedade atual (DEBORD, 2003, p. 19). 
Em meados de 2016, quando a terceira temporada da série Black Mirror chegou à plataforma Netflix, uma expressão foi popularizada nas redes sociais por aqueles que a acompanham: para cada acontecimento ou situação onde era perceptível o uso exagerado de tecnologias ou um exemplo da relação conflituosa dos indivíduos com elas, era utilizada a frase "Isso é tão Black Mirror!" como uma referência. A despeito do tom cômico que a expressão ganhou com o passar do tempo, a forte identificação entre a obra distópica e o mundo pós-moderno é sintomática: trata-se realmente de um futuro distante, ou a menção da tela preta dos aparatos tecnológicos tão caros aos sujeitos pós-modernos refere-se, na realidade, a uma espécie de abismo nietzschiano?

\section{CONTANDO-AVISOS: DE NARRATIVAS DISTÓPICAS E ALGUMAS (BREVES) NOTAS ANALÍTICAS}

Por muito tempo a forte presença de aspectos sociais e políticos na literatura foi encarada como uma espécie de "contaminação" da arte. Dessa forma, obras que continham apelo em torno de um desses aspectos (ou de ambos) não eram consideradas tão "puras" quanto as demais. Obviamente, com o passar do tempo, o surgimento de ideias de autores como Foucault e de movimentos como o feminismo, tais possibilidades separatistas entre literatura e sociedade foram entendidas como falhas ou inexistentes. Sabe-se que ignorar o elo entre literatura e sociedade é deixar em obscuro todo um universo de possibilidades e, sobretudo, de compreensão.

Partindo desse princípio, é facilmente compreensível que alguns autores se valham da literatura como objeto de elevação e transformação social. A esfera literária, a esfera artística, possui uma série de aparatos que auxiliam para tornar o seu poder de comunicação extremamente eficiente e, paradoxalmente, sensível. Seja na utilização criativa dos recursos de linguagem ou na inserção de pedaços da realidade em espaços de faz-de-conta, a literatura sempre encontra um meio. Não é por acaso que em tempos de extrema restrição comunicativa, como as ditaduras, por exemplo, a arte consiga se tornar tão fluida a ponto de se infiltrar em qualquer brecha e ainda continuar existindo e resistindo:

É nesse sentido que se pode dizer que a narrativa descobre a vida verdadeira, e que esta abraça e transcende a vida real. A literatura, com ser ficção, resiste à mentira. É nesse horizonte que o espaço da literatura, considerado em geral como o lugar da fantasia, pode ser o lugar da verdade mais exigente. (BOSI, 1997, p.27).

Neste processo, a literatura distópica assumiu desde sua criação a tarefa de comportar uma revelação essencial, talvez por isso a necessidade de empurrá-la a distância e projetá-la no futuro, bem como a de desfamiliarizá-la e transportá-la para lugar nenhum; é assim que a distopia consegue criticar um regime totalitário ainda pertencendo a este contexto. Com o advento da pós-modernidade e as transformações por ela desencadeadas é apenas natural que o gênero distópico siga esse rumo de mudança: se na modernidade a distopia refletia as ansiedades humanas, na pós-modernidade, o que vemos é o temor da realidade. 
A escritora norte-americana Suzanne Collins idealizou uma das obras distópicas mais populares da atualidade durante uma noite, em meados dos anos 2000, enquanto zapeava entre os canais de sua televisão. Segundo uma reportagem do Jornal Independent ${ }^{8}$, a combinação de alternar entre a exibição de um reality show de desafios, a cobertura da guerra no Iraque e o seu cansaço naquela noite, fez com que as imagens se misturassem na mente de Collins, dando vida ao cenário perturbador dos Jogos Vorazes:

As regras dos Jogos Vorazes são simples. Como punição pelo levante, cada um dos doze distritos deve fornecer uma garota e um garoto - chamados tributos - para participarem. Os 24 tributos serão aprisionados em uma vasta arena a céu aberto que pode conter qualquer coisa: de um deserto em chamas a um desencampado congelado. Por várias semanas os competidores deverão lutar até a morte. O último tributo restante será o vencedor (COLLINS, 2010, p. 24-25).

Os elementos que compõem a narrativa distópica contribuem grandiosamente para o seu apelo. O gênero compartilha da inquietude da pós-modernidade e apresenta sempre uma proposta aventurosa que integra um aviso. O fator de identificação que essas narrativas apresentam não se limita à dualidade de valores, tampouco do confronto entre mocinho $\mathrm{x}$ vilão, mas da experiência humana com o seu próprio tempo, com a sua própria história. Em Jogos Vorazes, temos a reflexão dos comportamentos espetaculares característicos da pós-modernidade, onde o cotidiano é preenchido por imagens, sobretudo, de violências: da vida: na naturalização e a espetacularização da morte; da liberdade: quando se assiste ao confinamento e à degradação humana de forma corrente, entre vários outros tipos; da humanidade: quando essas imagens deixam as telas e regram a vida. Apesar da presença do totalitarismo na obra de Collins, bem como os clássicos do século passado, o que se percebe é uma incômoda potencialidade a essa antiga ameaça: a tecnologia.

A obra Fahrenheit 451, de Ray Bradbury talvez tenha sido aquela que marcou o momento da mudança das reflexões apresentadas pelo gênero distópico. Na distopia de Bradbury, já é possível encontrar a já discutida verossimilhança que, ao que parece, vai acompanhar o gênero até a atualidade. Em Fahrenheit 451, temos a estória de uma cidade no futuro onde as casas são a prova de combustão, as pessoas conseguem interagir com as telas de suas televisões e, sobretudo, onde os livros foram proibidos:

— Você nunca lê nenhum dos livros que queima?

Ele riu.

- Isso é contra a lei!

- Ah, é claro.

— É um trabalho ótimo. Segunda-feira, Millay; quarta-feira, Whitman;

8 WALKER, Tim. Suzanne Collins' Hunger Games trilogy speaks to a generation of teenage readers like no other literary creation - but what's the big message?. Disponível em < https://www.independent.co.uk/arts-entertainment/films/ features/suzanne-collins-hunger-games-trilogy-speaks-to-a-generation-of-teenage-readers-like-no-other-8958113.html $>$ Acesso em 10 de Set. 2018. 
sexta-feira, Faulkner. Reduza os livros às cinzas e, depois, queime as cinzas. Este é o nosso slogan oficial (BRADBURY, 2012, p. 18-19).

Na obra de Bradbury, os bombeiros deixaram sua função original e assumiram o trabalho de caçar e queimar os exemplares de livros ainda existentes. Ao contrário de seus "irmãos" mais velhos, Fahrenheit 451 não nos apresenta um grande e nefasto líder onipresente (não como o Grande Irmão de 1984, por exemplo). Apesar da proibição dos livros, esta sociedade não se importa mais com eles. Mesmo que muitos possuam a capacidade de leitura, os habitantes da cidade de Fahrenheit 451 preferem gastar seu tempo com a ingestão de narcóticos e com programas de televisão que projetam uma espécie de "realidade" interativa:

O que interessa aqui, porém, é frisar a singularidade da distopia de Bradbury. Pois enquanto Huxley e Orwell escreveram seus livros sob o impacto dos regimes totalitários (nazismo e stalinismo), Bradbury percebe o nascimento de uma forma mais sutil de totalitarismo: a indústria cultural, a sociedade de consumo e seu corolário ético - a moral do senso comum (PINTO, 2012 apud BRADBURY, 2012, p. 12).

A distopia de Bradbury não possui características futurísticas extraordinárias em sua composição, vemos, no entanto, aparatos que contribuem para a abstração geral dos sujeitos, o que gerou um padrão de comportamento social inquestionavelmente perturbador. Os livros desapareceram há muito tempo, assim como cursos de ciências humanas, professores, filósofos e sociólogos. Todas as figuras e escritos que apresentam algum tipo de provocação, ou algo que ameace a felicidade coletiva, são rapidamente destruídos.

O estado de felicidade induzido pela interação com dispositivos tecnológicos e drogas é legitimado pela aceitação das pessoas. Não há momentos de dúvida, não há rebelião ou insegurança. Sem livros não há memória, não há melancolia ou consciência crítica, apenas felicidade cega e permanente:

Lembre-se, os bombeiros raramente são necessários. O próprio público deixou de ler por decisão própria. Vocês, bombeiros, de vez em quando garantem um circo em volta do qual multidões se juntam para ver a bela chama de prédios incendiados, mas, na verdade, é um espetáculo secundário, e dificilmente necessário para manter a ordem. São muito poucos os que ainda querem ser rebeldes. E desses poucos, a maioria, como eu, facilmente se intimida. Você consegue dançar mais depressa que o Palhaço Branco, gritar mais alto que o "Senhor Bugiganga" e a "família” do salão? Se puder, conseguirá o que quer, Montag. Em todo caso, você é um tolo. As pessoas estão é se divertindo (BRADBURY, 2012, p. 69).

Fahrenheit 451 antecipa e endossa a crítica revivida em Jogos Vorazes: 52 anos se passaram e o mundo criado por Bradbury, que já não parecia ser tão distante assim para a época, soa, hoje, incrivelmente familiar. Essa capacidade de "premonição" dos autores de distopia não é fruto do acaso; por ser uma projeção dos receios de uma geração, represen- 
tada pelo autor, a visão crítica e sensível dos escritores geralmente antecipa caminhos que a sociedade já está percorrendo, embora não tenha se dado conta.

A relação intrínseca que o gênero distópico possui com os medos universais invoca-nos a imagem dos clássicos contos de tradição oral que, antes mesmo de serem escritos ou se tornarem os sucessos remodelados da Disney, eram contados de geração para geração. O conteúdo desses contos não se tratava de narrativas felizes, mas de histórias de terror contadas em tom de aviso para as pessoas, principalmente as crianças, como um dispositivo de segurança:

Levar as crianças de nossos distritos, forçá-las a matar umas às outras enquanto todos nós assistimos pela televisão. Essa é maneira encontrada pela Capital de nos lembrar de como estamos totalmente subjugados a ela. De como teríamos pouquíssimas chances de sobrevivência caso organizássemos uma nova rebelião. Pouco importa as palavras que eles utilizam. A mensagem é bem clara: "Vejam como levamos suas crianças e as sacrificamos, e não há nada que vocês possam fazer a respeito. Se erguerem um dedo nós destruiremos todos vocês da mesma maneira que destruímos o Distrito Treze" (COLLINS, 2010, p. 25).

Um mundo onde os livros foram banidos, um mundo onde as pessoas perderam o senso de humanidade, um mundo onde o governo sanciona e televisiona a morte de crianças... escolha um medo pós-moderno e a distopia já narrou. De certa forma a distopia, com sua natureza crítica, antecipatória e pessimista, é o próprio conto de aviso da contemporaneidade. É perceptível como ela privilegia a tecnologia, sua relação e seus efeitos na humanidade, bem como a progressão da ambição dos homens, pois essas são as nossas maiores ansiedades:

(...) the dystopian imagination has served as a prophetic vehicle, the canary in a cage, for writers with an ethical and political concern for warning us of terrible sociopolitical tendencies that could, if continued, turn our contemporary world into the iron cages portrayed in the realm of Utopia's underside (BACCOLINI and MOYLAN, 2003, p. 1-2)

A distopia fala dos medos, que por si só já diz respeito ao temor do presente pelo que pode acontecer; ela concede um vislumbre do resultado das atitudes e (más) ações humanas, dessa forma, quem sabe, podem ser refletidas e evitadas. Em sua variação contemporânea, no entanto, tais narrativas parecem iniciar uma importante mudança: além do novo direcionamento (grande parte das obras distópicas contemporâneas são escritas para o público jovem adulto. Jogos Vorazes é um exemplo), as narrativas distópicas utilizam o medo e o pessimismo como uma progressão para reflexão e para a apresentação de uma possibilidade esperançosa:

(...) the dystopian imagination has served as a prophetic vehicle, the canary in a cage, for writers with an ethical and political concern for warning us of terrible 
sociopolitical tendencies that could, if continued, turn our contemporary world into the iron cages portrayed in the realm of Utopia's underside ${ }^{9}$ (BACCOLINI and MOYLAN, 2003, p. 1-2)

A distopia fala dos medos, que por si só já diz respeito ao temor do presente pelo que pode acontecer; ela concede um vislumbre do resultado das atitudes e (más) ações humanas, dessa forma, quem sabe, podem ser refletidas e evitadas. Em sua variação contemporânea, no entanto, tais narrativas parecem iniciar uma importante mudança: além do novo direcionamento (grande parte das obras distópicas contemporâneas são escritas para o público jovem adulto. Jogos Vorazes é um exemplo), as narrativas distópicas utilizam o medo e o pessimismo como uma progressão para reflexão e para a apresentação de uma possibilidade esperançosa:

Dystopian thought can serve as a valuable corrective to this tendency, and therefore should be thought of as working with rather than against utopian thought. In the final analysis, the most important contribution of dystopian thought may be to provide opposing voices that challenge utopian ideals, thus keeping those ideals fresh and viable and preventing them from degenerating into dogma. By taking dystopian fiction seriously and by using the dystopian impulse as a focal point for polyphonic confrontations among literature, popular culture, and social criticism we as readers can contribute to this challenge, which is ultimately a positive one. Indeed, it may be that dystopian warnings of impending nightmares are ultimately necessary to preserve any possible dream of a better future $^{10}$ (BOOKER, 1994, p. 177).

A distopia foi e é importantíssima em todas as suas vertentes. Como Booker afirma na citação acima, o pensamento distópico cumpre a sua função primeira de servir como oposição à utopia, especialmente a ideológica, o que é essencial, visto os catastróficos resultados do idealismo social desenfreado. Ao exercitar a reflexão crítica que a distopia fornece, estamos também fazendo a reflexão de nós mesmos e isso, por si só, já é uma positividade. As narrativas distópicas contemporâneas já instigam também uma tendência na literatura distópica: uma visível interseção com a utopia que pode ser percebida em seus novos finais esperançosos. Afinal, a perspectiva de um futuro melhor (utopia) é tão necessária quando as rédeas (distopia) para que este possa realmente ser o melhor para todos.

9 (...) a imaginação distópica servi de veículo profético, o canário em uma jaula, para escritores com uma preocupação ética e política de nos alertar de terríveis tendências sociopolíticas que poderiam, se continuássemos, transformar nosso mundo contemporâneo nas gaiolas de ferro retratadas no reino do lado inferior da utopia.

10 O pensamento distópico pode servir como um valioso corretivo para essa tendência e, portanto, deve ser idealizado para trabalhar em parceria com o pensamento utópico e não contra ele. Em última análise, a contribuição mais importante do pensamento distópico pode ser fornecer vozes opostas que desafiem os ideais utópicos, mantendo assim esses ideais frescos e viáveis e impedindo-os de se degenerarem em dogma. Levando a ficção distópica a sério e usando o impulso distópico como um ponto focal para confrontos polifônicos entre literatura, cultura popular e crítica social, nós, como leitores, podemos contribuir para esse desafio, que é em última análise positivo. De fato, pode ser que os avisos distópicos de pesadelos iminentes sejam, por fim, necessários para preservar qualquer possível sonho de um futuro melhor (tradução nossa). 


\section{CONSIDERAÇÕES FINAIS}

É certo que a pós-modernidade, com seu movimento poderoso de ruptura e dissolução, criou novas formas de conceber o mundo e trouxe novas influências que regulam a vida prática. Nunca antes na história da humanidade houve um momento como o pós-moderno e nunca antes mulheres e homens tiveram que lidar com as transformações e os efeitos das tecnologias, da internet e da mídia como agora: a experiência do sujeito pós-moderno é imprevisível e única. Assim, a sensação de desestabilidade e de abandono é um desafio que deve ser superado constantemente. Caso contrário, a tendência por buscar a solidez perdida (a reconciliação entre segurança e liberdade) e recriar certos padrões do passado é irresistível. Bauman já fala de uma "negação da negação da utopia" (2017, p. 13), a retrotopia, uma espécie de romantização de ideias e estruturas do passado que surge da desilusão com a pós-modernidade. Esse é um perigo que espreita a cada virada desse novo tempo: a história nem sempre é um aviso forte o suficiente para combater a aspiração e a ação humana. A literatura e as outras artes têm hoje e sempre um papel de base para a promoção da autorreflexão e crítica do humano, um compromisso com a criação de espaços de liberdade. Dessa forma, esse momento inédito em que nos encontramos é um momento tão propício quanto qualquer outro para a análise de obras de arte. Acompanhar as transformações da literatura, considerá-las não apenas como sintomas, é um trabalho que não deve ser ignorado. Não se pode negar que a pós-modernidade permite, e novamente é preciso apontar, a existência e divulgação de novas vozes, discursos, experiências.

A distopia não é a única possibilidade complexa que pode ser encontrada na literatura contemporânea, mas, talvez, seja a que mais contempla as problemáticas e a experiência do sujeito pós-moderno, pois explora diversos vetores do seu universo. Ao amplificar essas problemáticas e críticas e fixá-las em um lugar nenhum, o gênero expõe o presente e mapeia o futuro, permitindo-nos um lugar de pausa para a reflexão, tão necessária no movimento de fluidez do tempo presente. Estudar a distopia é, ao mesmo tempo, considerar um gênero emergente e as pegadas de um futuro que emerge. Tão importante quanto conhecer como chegamos aqui não é saber para onde nos encaminhamos, mas como chegaremos lá. 


\section{REFERÊNCIAS:}

BAUMAN, Zygmunt. Modernidade líquida. Trad. de Plínio Dentzien. Rio de Janeiro: Jorge Zahar Ed, 2000.

Arte da vida. Trad. de Carlos Alberto Medeiros. Rio de Janeiro: Zahar, 2009.

Retrotopia. Trad. de Renato Aguiar. Rio de Janeiro: Zahar, 2017.

BACCOLINI, Raffaella \& Tom MOYLAN (eds). Dark Horizons: Science Fiction and the Dystopian Imagination. London: Routledge, 2003.

BERMAN, Marshall. Tudo o que é sólido desmancha no ar: a aventura da modernidade. São Paulo: Companhia das Letras, 1982. Medeiros. Rio de Janeiro: Jorge Zahar Ed, 2009.

BRADBURY, Ray. Fahrenheit 451. Trad. de Cid Knipel. Prefácio de Manuel Costa Pinta. $-2^{a}$ ed. São Paulo: Globo, 2012.

BOSI, Alfredo. Narrativa e resistência. In: Literatura e resistência. São Paulo: Companhia das Letras, 2002, p. 118-135.

BOOKER, M. Keith. The Dystopian Impulse in Modern Literature: Fiction as Social Criticism. Westport, Conn: Greenwood, 1994.

COLLINS, Suzanne. Jogos Vorazes. Trad. de Alexandre D’Elia. Rio de Janeiro: Rocco Jovens Leitores, 2010.

CLAEYS, Gregory. Dystopia: A Natural History. United Kingdom: Oxford University Press, 2017.

DEBORD, Guy. A sociedade do espetáculo: 2003. Disponível em: <http://www.ebooksbrasil.org/ adobeebook/socespetaculo.pdf. Acesso em: 28. Jun. 2015.

HARVEY, David. A condição pós-moderna. São Paulo: Edições Loyola. 2008.

HUXLEY, Aldous. Admirável mundo novo. Trad. de Lino Vallandro, Vidal Serrano. 22a ed. São Paulo: Globo, 2014.

PINTO, Manuel da Costa. Prefácio. In: BRADBURY, Ray. Fahrenheit 451. Trad. de Cid Knipel. Prefácio de Manuel Costa Pinta. - 2a ed. São Paulo: Globo, 2012.

SANTOS, Jair Ferreira dos. O que é pós-moderno. São Paulo: Brasiliense, 2004. 
